\title{
E. Aschieri, Lamartine e l'Italia. Aspetti di una fortuna (1820-1848)
}

\section{Annalisa Bottacin}

\section{Q OpenEdition}

1 Journals

\section{Edizione digitale}

URL: https://journals.openedition.org/studifrancesi/39577

DOI: 10.4000/studifrancesi.39577

ISSN: 2421-5856

\section{Editore}

Rosenberg \& Sellier

\section{Edizione cartacea}

Data di pubblicazione: 1 décembre 2004

Paginazione: 389-390

ISSN: 0039-2944

\section{Notizia bibliografica digitale}

Annalisa Bottacin, «E. Aschieri, Lamartine e l'Italia. Aspetti di una fortuna (1820-1848)», Studi Francesi [Online], 143 (XLVIII | II) | 2004, online dal 30 novembre 2015, consultato il 19 mai 2021. URL: http:// journals.openedition.org/studifrancesi/39577 ; DOI: https://doi.org/10.4000/studifrancesi.39577

Questo documento è stato generato automaticamente il 19 mai 2021.

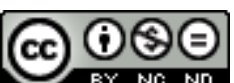

Studi Francesi è distribuita con Licenza Creative Commons Attribuzione - Non commerciale - Non opere derivate 4.0 Internazionale. 


\title{
E. Aschieri, Lamartine e l'Italia. Aspetti di una fortuna (1820-1848)
}

\author{
Annalisa Bottacin
}

\section{NOTIZIA}

E. ASCHIERI, Lamartine e l'Italia. Aspetti di una fortuna (1820-1848), Paris, Champion, 2000

(«Centre d'Etudes Franco-Italiennes. Université de Turin et de Savoie - Bibliothèque Franco Simone n. 31. Sous la direction de Pierre BLANC, Lionello SOZZI et Louis TERREAUX), pp. 367.

1 Il bel volume di Elena Aschieri, docente all'Université Stendhal di Grenoble, dedicato alla ricognizione dei soggiorni italiani di Alphonse de Lamartine ha un duplice merito. Innanzitutto introduce ordinatamente il lettore alla ricezione, da parte della critica del nostro paese, dell'opera del poeta di Mâcon - di cui è ricorso nel 1990 il bicentenario della nascita - relativa agli anni tra il 1820 e il 1848 che furono, come rileva la studiosa nella Premessa (pp. 11-19) «[a]nni particolarmente significativi per il nostro autore, che nel 1820 pubblica quelle Méditations poétiques - considerate unanimamente, già dalla critica ottocentesca, il suo capolavoro - e che nel 1848 conclude con la presidenza della repubblica francese una carriera politica estremamente intensa. Dopo il 1848 prosegue Aschieri - Lamartine è ormai un monstrum sacrum consegnato al mito e alla storia, il che, nel bene e nel male, segna anche l'evoluzione della fortuna» (p. 12). In secondo luogo viene posto in questo lavoro l'interesse su uno studio dell'alta figura del politico e dell'uomo di lettere dinanzi alla cultura italiana dell'epoca. I vari soggiorni italiani di Lamartine (che tra l'altro tra il 1825 e il 1827 fu secrétaire de légation a Firenze, dove ebbe occasione di incontrare anche Stendhal, che sovente si recava nella città granducale, come si legge nel Cours familier de littérature), che si snodano tra il 1811 e il 1848, lo fecero entrare in contatto con l'intellighenzia del tempo; come ben ricorda Aschieri, Lamartine fu tra l'altro in relazione con Alessandro Manzoni, che ebbe a 
elogiare i versi delle Méditations poétiques, dove lo stesso Lamartine aveva lodato I Promessi sposi.

2 È nel primo capitolo della prima parte, intitolato Storia di una ricezione: la critica (pp. 17-97), denso e assai ben documentato, che vengono messi in evidenza tali incontri e, di conseguenza, l'inizio di lavori critici - per lo più recensioni - e di traduzioni, come quelle attribuite a Cesare d'Azeglio, non sempre favorevoli per diversa impostazione ideologica, o le indagini di Achille Mauri, autore «di un articolo 'fondatore' della critica lamartiniana in Italia» (p. 37) che Aschieri riporta nella seconda Appendice (pp. 237-75), situata nella seconda parte.

Il secondo capitolo è dedicato alle traduzioni italiane dell'opera di Lamartine (pp. 99-161); dalla prima idea, che pare comunque non attuata e di cui non resta traccia, del 1820 dell'amico del poeta, Virieu, ai primi effettivi traduttori. Assai interessante la pubblicazione del Repertorio delle singole traduzioni ed edizioni italiane (1820-1848) dalle Méditations poétiques al Voyage en Orient a Jocelyn (pp. 110-68), che evidenzia l'ascolto lamartiniano nel nostro paese durante il Romanticismo e il Risorgimento, che si completa, nel terzo capitolo, delle arricchenti Schede biografiche dei critici e dei traduttori (pp. 169-203). Il volume si avvalora altresì di tre appendici (della seconda abbiamo già riferito). La prima comprende un Repertorio degli articoli e delle raccolte di traduzioni che testimoniano la ricezione di Lamartine in Italia (pp. 208-33) e la terza segnala accuratamente le Biblioteche perlustrate dalla studiosa nella sua puntuale ricerca (pp. 279-88). Un'esaustiva e aggiornata bibliografia chiude quest'importante e innovativo studio sul percorso italiano del grande poeta francese. 